\title{
Unabated anorexic and enhanced thermogenic responses to melanotan II in diet-induced obese rats despite reduced melanocortin 3 and 4 receptor expression
}

\author{
G Li ${ }^{1}$, Y Zhang ${ }^{1,2}$, J T Wilsey ${ }^{1,2}$ and P J Scarpace ${ }^{1,2}$ \\ ${ }^{1}$ Department of Pharmacology and Therapeutics, University of Florida College of Medicine, Gainesville, Florida 32610, USA \\ ${ }^{2}$ Geriatric Research, Education and Clinical Center (182), Department of Veterans Affairs Medical Center, Gainesville, Florida 32608-1197, USA \\ (Requests for offprints should be addressed to P J Scarpace, Geriatric Research, Education and Clinical Center, Malcolm Randall Veterans Affairs Medical \\ Center, Gainesville, Florida 32608-1197, USA; Email: scarpace@ufl.edu)
}

\begin{abstract}
The effects of the chronic activation of the central melanocortin (MC) system by melanotan II (MTII) were assessed in chow-fed $(\mathrm{CH})$ and high-fat $(\mathrm{HF})$ diet-induced obese (DIO) Sprague-Dawley rats. Six-day central infusion of MTII (1 nmol/day) reduced body weight and visceral adiposity compared with ad libitum-fed control and pairfed groups and markedly suppressed caloric intake in both $\mathrm{CH}$ and DIO rats. The anorexic response to MTII was similar in DIO relative to $\mathrm{CH}$ rats. MTII induced a sustained increase in oxygen consumption in DIO but a delayed response in $\mathrm{CH}$ rats. In both diet groups, MTII reduced serum insulin and cholesterol levels compared with controls. HF feeding increased brown adipose tissue (BAT) uncoupling protein 1 (UCP1) by over twofold, and UCP1 levels were further elevated in MTII-treated CH and DIO rats. MTII lowered acetyl-CoA carboxylase
\end{abstract}

expression and prevented the reduction in muscle-type carnitine palmitoyltransferase I mRNA by pair-feeding in the muscle of DIO rats. Compared with $\mathrm{CH}$ controls, hypothalamic MC3 and MC4 receptor expression levels were reduced in DIO controls. This study has demonstrated that, despite reduced hypothalamic MC3/MC4 receptor expression, anorexic and thermogenic responses to MTII are unabated with an initial augmentation of energy expenditure in DIO versus $\mathrm{CH}$ rats. The HFinduced up-regulation of UCP1 in BAT may contribute to the immediate increase in MTII-stimulated thermogenesis in DIO rats. MTII also increased fat catabolism in the muscle of DIO rats and improved glucose and cholesterol metabolism in both groups.

Journal of Endocrinology (2004) 182, 123-132

\section{Introduction}

Melanocortins (MCs) are bioactive peptides derived from a common pre-hormone, pro-opiomelanocortin (POMC). Among them, $\alpha$-melanocyte stimulating hormone ( $\alpha$ $\mathrm{MSH}$ ) is a major regulator of feeding and body weight via hypothalamic MC3 and 4 receptors (MC3R and MC4R) (Cone 1999). Central infusion of $\alpha-\mathrm{MSH}$ or its synthetic agonists causes anorexia and weight loss (Poggioli et al. 1986, Fan et al. 1997, Grill et al. 1998), whereas infusion of MCR blockers or over-production of the endogenous MCR antagonist, agouti-related protein (AgRP), produces hyperphagia and obesity (Fan et al. 1997, Graham et al. 1997, Ollmann et al. 1997, Hagan et al. 1999). Knockout studies of the central MC3R and MC4R have identified these receptors as important players in energy homeostasis (Huszar et al. 1997, Chen et al. 2000). Targeted disruption of the MC4R gene leads to overfeeding and obesity (Huszar et al. 1997), whereas MC3R knockouts over-accumulate fat with minimal changes in caloric intake (Chen et al. 2000). Deficiency in POMC also results in increased food intake and morbid obesity in both rodents and humans (Krude et al. 1998, Yaswen et al. 1999). Apparently, the central MC system has critical functions in the homeostatic regulation of body weight.

One of the hallmarks of obesity, whether it is genetic, diet induced or age related, is leptin resistance. Human obesity as well as many rodent models of obesity is accompanied by elevated serum leptin and leptin resistance, which becomes more pronounced with progressive degrees of obesity. Diet-induced obese (DIO) rodent models, characterized by hyperleptinemia and hyperinsulinemia, somewhat resemble the onset of human obesity and hence provide a valuable tool for investigating leptin resistance in humans. The nature of leptin resistance associated with DIO animals is not well understood. The blunted responsiveness to both endogenous and exogenous leptin has been, in part, attributed to defects in the blood-brain barrier transport system (peripheral resistance) (Burguera et al. 2000) and in leptin signal transduction in 
the hypothalamic leptin-responsive neurons (central resistance) (El Haschimi et al. 2000, Scarpace et al. 2001). A growing body of evidence suggests that the MC system is located downstream of the hypothalamic leptin-signaling pathway. Leptin activates POMC- and suppresses AgRPcontaining neurons of the ventrolateral and ventromedial arcuate nucleus respectively, resulting in an increase in the expression of POMC and a reduction in AgRP (Schwartz et al. 1996, 1997, Cheung et al. 1997, Baskin et al. 1999, Elias et al. 2000). It is possible that the central resistance is partially due to a failure of the leptin signal to activate POMC or suppress AgRP neurons so that the proper regulation of POMC and AgRP expression by leptin is lost. As a result, leptin-initiated MC activation is impaired. In support of this notion, $\alpha-\mathrm{MSH}$ and a potent $\mathrm{MC}$ agonist, melanotan II (MTII), as well as central POMC gene therapy were effective in obese Zucker rats with defective leptin receptor signaling (Hwa et al. 2001, Cettour-Rose \& Rohner-Jeanrenaud 2002, Li et al. 2003) and in DIO mice with leptin resistance (Pierroz et al. 2002). Chronic impairment in MC activation may generate hypersensitivity (or hyper-responsiveness) of the $\mathrm{MC}$ pathway to pharmacological MC stimulation, potentially through homeostatic up-regulation of MC3R and MC4Rs. This postulated hypersensitivity has been indicated in two studies, one demonstrating enhanced responses to MTII in obese Zucker rats (Cettour-Rose \& Rohner-Jeanrenaud 2002) and another reporting an acute enhanced anorexic response to $\alpha-\mathrm{MSH}$ in leptin-resistant DIO rats (Hansen et al. 2001). However, a recent study indicated that high-fat (HF) feeding actually decreased the anorexic effects of MTII, which could contribute to diet-induced obesity (Clegg et al. 2003). Since most of these previous reports assessed the acute responses to MCs, one of our aims was to determine the chronic effects of central infusion of MTII in a DIO rat model with a normal genetic background. We also examined whether dietinduced obesity alters the expression levels of hypothalamic MC3R and MC4R that may potentially mediate the differential response to MTII in DIO compared with lean animals. Furthermore, because of the scarcity of information on how $\alpha-\mathrm{MSH}$ influences energy expenditure and body metabolism (in contrast to plentiful information about the effect of $\alpha-\mathrm{MSH}$ and its analogs on food intake), we assessed the thermogenic response as well as fat metabolism in brown adipose tissue (BAT) and skeletal muscle following central MTII administration in both lean and DIO rats.

To this end, we examined the effects of a 6-day central administration of leptin or MTII on energy balance, BAT thermogenesis, and indicators of skeletal muscle fat metabolism in chow-fed $(\mathrm{CH})$ lean and DIO Sprague-Dawley rats. Food intake, body weight, adiposity, serum hormone and metabolite levels, oxygen consumption, BAT uncoupling protein 1 (UCP1) protein, expression of acetyl-CoA carboxylase (ACC) and muscle-type carnitine palmitoyl- transferase I (M-CPT I) in soleus muscle and MC3R and $\mathrm{MC} 4 \mathrm{R}$ in the hypothalamus were measured.

\section{Materials and Methods}

Animals and diets

Fourteen-week-old female Sprague-Dawley rats were obtained from Taconic (Germantown, NY, USA). Upon arrival, rats were examined and remained in quarantine for 1 week. Animals were cared for in accordance with the principles of the NIH Guide to the Care and Use of Experimental Animals. Rats were housed individually with a $12 \mathrm{~h}$ light: $12 \mathrm{~h}$ darkness cycle (0700-1900 h). Standard rat chow (15\% fat; $3.3 \mathrm{kcal} / \mathrm{g}$ diet 2018; Harlan Teklad, Madison, WI, USA) and water were provided ad libitum. At the start of the experiment, 30 rats were maintained on chow $(\mathrm{CH})$, whereas 70 rats were switched to an HF diet $(60 \%$ fat; $5 \cdot 2 \mathrm{kcal} / \mathrm{g}$ D12492; Research Diets, New Brunswick, NJ, USA) for 10 weeks. The top $40 \%$ of weight gainers on the HF diet were designated as DIO whereas the rest were removed from the study. DIO and $\mathrm{CH}$ animals remained on their respective diets through the conclusion of the study. At the end of the 10-week feeding period, levels of serum leptin (collected from the tail) were assessed in representative subgroups of $\mathrm{DIO}$ and $\mathrm{CH}$ animals.

\section{Experiment 1: 6-day intracerebroventricular (i.c.v.) administration of leptin}

$\mathrm{CH}$ or DIO rats were infused with either artificial cerebrospinal fluid (ACSF; $148 \mathrm{mM} \mathrm{NaCl}, 3 \mathrm{mM} \mathrm{KCl}$, $0.8 \mathrm{mM} \mathrm{MgCl}, 1.4 \mathrm{mM} \mathrm{CaCl}, 1.5 \mathrm{mM} \mathrm{Na}_{2} \mathrm{HPO}_{4}$, $0 \cdot 2 \mathrm{mM} \mathrm{NaH}{ }_{2} \mathrm{PO}_{4}, 0.1 \mathrm{mg} / \mathrm{ml}$ bovine serum albumin) (six to seven per group) or recombinant mouse leptin $(10 \mu \mathrm{g} /$ day, five to seven per group) into the left lateral ventricle by mini-osmotic pumps (Alzet 2001; Durect, Cupertino, CA, USA) for 6 days. Under $6 \mathrm{mg} / \mathrm{kg}$ xylazine (Phoenix Pharmaceutical, St Joseph, MO, USA) and $60 \mathrm{mg} / \mathrm{kg}$ ketamine (Monarch Pharmaceuticals, Bristol, TN, USA) anesthesia, a cannula (Brain Infusion Kit II; Durect) was stereotaxically placed into the left lateral ventricle using the following co-ordinates: $0.8 \mathrm{~mm}$ posterior to bregma, $1.4 \mathrm{~mm}$ lateral to the midsaggital suture, and to a depth of $4 \mathrm{~mm}$. The brain infusion cannula was anchored to the skull using acrylic dental cement and a small stainless steel screw. A catheter was connected from the cannula to the mini-osmotic pump flow moderator. The pump was inserted into a subcutaneous pocket on the dorsal surface. Rats were kept warm until fully recovered and were provided with a highly palatable Jell-O mixture consisting of Jell-O (Kraft Foods, Rye Brook, NY, USA), Ensure Plus (Abbott Laboratories, Columbus, OH, USA), STAT (PRN pharmacal, Pensacola, FL, USA) and soy protein booster (Naturade; Irvine, CA, USA) at day 1 to 
alleviate the anorexic effect elicited by surgical intervention. Chow or HF diet resumed from day 2, and rats were allowed access to food ad libitum. Food consumption and body weight were recorded for 6 days. Oxygen consumption was monitored at days 2 and 6 . All rats were killed at the end of the dark cycle of day 6 and tissues harvested for analysis.

\section{Experiment 2: 6-day i.c.v. administration of MTII}

$\mathrm{CH}$ and DIO rats were infused with either ACSF (control and pair-fed groups, six to eight per group) or MTII $(1 \mathrm{nmol} /$ day, six to nine per group, Phoenix Pharmaceuticals, Belmont, CA, USA) into the left lateral ventricle by mini-osmotic pump (Alzet 2001) for 6 days. Rats were provided with the highly palatable Jell-O mixture at day 1, and chow or HF diet was resumed from day 2. Control and MTII-treated rats were allowed access to food ad libitum, whereas pair-fed rats were pair-fed to the amount of food consumed by the MTII-treated rats. Daily food consumption and body weight were recorded for 6 days. Oxygen consumption was monitored at days 2 and 6. All rats were killed at the end of the dark cycle of day 6 and tissues harvested for analysis.

\section{Oxygen consumption}

Oxygen consumption was assessed in up to four rats simultaneously with an Oxyscan analyzer (OXS-4; Omnitech Electronics, Columbus, OH, USA) as described previously (Scarpace et al. 1992). Flow rates were 2 liters/min with a 30-s sampling time at 5-min intervals. The rats were placed into the chamber for $90 \mathrm{~min}$ with the oxygen consumption values for the last $30 \mathrm{~min}$ (when their oxygen consumption had reached stable levels) used in the calculations. Food was not available during the measurement. Results are expressed as mass-adjusted consumption $\left(\mathrm{ml} / \mathrm{min}\right.$ per $\left.\mathrm{kg}^{0.75}\right)$.

\section{Tissue harvesting and preparation}

Rats were killed by cervical dislocation under $85 \mathrm{mg} / \mathrm{kg}$ pentobarbital anesthesia. Blood samples were collected by heart puncture and serum was harvested by a 15-min centrifugation in serum separator tubes. The circulatory system was perfused with $30 \mathrm{ml}$ cold saline and BAT, perirenal (PWAT) and retroperitoneal white adipose tissues (RTWAT), and a portion of the red soleus muscle were excised. The hypothalamus was removed by making an incision medial to piriform lobes, caudal to the optic chiasm, and anterior to the cerebral crus to a depth of 2-3 mm. Tissues were stored at $-80{ }^{\circ} \mathrm{C}$ until analysis. For Western analysis, BAT were homogenized in $0.3 \mathrm{ml}$ $10 \mathrm{mM}$ Tris-HCl, $\mathrm{pH} 6 \cdot 8,2 \%$ SDS, and $0.08 \mu \mathrm{g} / \mathrm{ml}$ okadaic acid. Protease inhibitors, $1 \mathrm{mM}$ phenylmethylsulfonyl fluoride, $0 \cdot 1 \mathrm{mM}$ benzamidine, and $2 \mu \mathrm{M}$ leupeptin were also present. Homogenates were immediately boiled for $2 \mathrm{~min}$, cooled on ice, and stored frozen at $-80{ }^{\circ} \mathrm{C}$. Protein was determined using the DC protein assay kit (Bio-Rad, Hercules, CA, USA). BAT samples were filtered through a $0.45 \mu \mathrm{m}$ syringe filter (Whatman, Clifton, NJ, USA) to remove lipid particles prior to protein measurements.

\section{Serum leptin, insulin, glucose, and cholesterol}

Serum leptin levels were measured using a rodent leptin ELISA kit (Crystal Chem, Chicago, IL, USA). Serum insulin levels were measured with rat insulin RIA kits (Linco Research, St Charles, MO, USA). Total cholesterol was determined by enzymatic colorimetric kits from WAKO Chemicals (Neuss, Germany). Serum glucose was assessed via a colorimetric reaction with Trinder, the Sigma diagnostics glucose reagent (St Louis, MO, USA).

\section{BAT UCP1 protein}

UCP1 levels were determined by immunoreactivity in BAT homogenates. BAT samples $(20 \mu \mathrm{g})$ prepared as described above were separated on an SDS-PAGE gel and electrotransferred to nitrocellulose membrane. Immunoreactivity was assessed on separate membranes with an antibody specific to rat UCP1 (Linco Research). Immunoreactivity was visualized by enhanced chemiluminescent detection (Amersham Pharmacia Biotech) and quantified by video densitometry (Bio-Rad).

\section{Relative quantitative RT-PCR}

$\mathrm{ACC}$ and M-CPT I expression in the soleus muscle and MC3R and MC4R mRNA levels in the hypothalamus were identified by relative quantitative RT-PCR using QuantumRNA 18S internal standards kit (Ambion, Austin, TX, USA). Total cellular RNA was extracted as described (Li et al. 2002) and treated with RNase-free DNase (Ambion). First-strand cDNA synthesis was generated from $2 \mu \mathrm{g}$ RNA in a $20 \mu \mathrm{l}$ volume using random primers (Life Technologies, Rockville, MD, USA) containing 200 units M-MLV reverse transcriptase (Life Technologies). Relative quantitative PCR was performed by multiplexing corresponding primers (ACC sense 5'-GCTTGCAAACTCGACCTCTC-3', antisense 5'CTTGATGATGGCGTTCTTGA-3'; M-CPT I sense 5'-GCAAACTGGACCGAGAAGAG-3', antisense 5'CCTTGAAGAAGCGACCTTG-3'; MC3R sense 5'AGCAACCGGAGTGGCAGT-3', antisense 5'-GGCC ACGATCAAGGAGAG-3'; MC4R sense $5^{\prime}$-AGTCTC TGGGGAAGGGGCA-3', antisense $5^{\prime}$-CAACTGATG ATGATCCCGAC-3'), $18 \mathrm{~S}$ primers, and competimers and coamplifying. Linearity for ACC and M-CPT I amplicons was determined to be between 26 and 36 cycles, 18 and 32 for MC3R and 24 to 44 for MC4R. The 
Table 1 Body weight (BW) and serum leptin levels of $\mathrm{CH}$ and $\mathrm{HF}$ $\mathrm{DIO}$ rats after 10 weeks of diet. Values are means \pm S.E.

\begin{tabular}{|c|c|c|}
\hline \multirow{2}{*}{\multicolumn{3}{|c|}{ DIO }} \\
\hline & & \\
\hline Baseline (g) & $291 \cdot 1 \pm 4 \cdot 1$ & $291.9 \pm 4.9$ \\
\hline Week $10(\mathrm{~g})$ & $333 \cdot 6 \pm 5 \cdot 5$ & $372 \cdot 4 \pm 7 \cdot 0^{*}$ \\
\hline BW gain (g) & $42 \cdot 5 \pm 4 \cdot 5$ & $80 \cdot 6 \pm 3 \cdot 4^{*}$ \\
\hline Serum leptin $(\mathrm{ng} / \mathrm{ml})$ & $5 \cdot 32 \pm 0 \cdot 47$ & $11 \cdot 34 \pm 1 \cdot 50^{*}$ \\
\hline
\end{tabular}

Thirty and 70 rats were started on the chow $(3.3 \mathrm{kcal} / \mathrm{g})$ or $\mathrm{HF}(5 \cdot 2 \mathrm{kcal} / \mathrm{g})$ diet respectively. The top $40 \%$ of weight gainers consuming the HF diet at the end of 10 weeks of feeding were designated as DIO $(n=27)$. Serum leptin levels were measured in $7 \mathrm{CH}$ and $10 \mathrm{DIO}$ rats at end of 10 weeks of feeding

${ }^{\star} P$ at least $<0.01$ vs $\mathrm{CH}$ (unpaired $t$-test).

optimum ratio of $18 \mathrm{~S}$ primer to competimer was 1:9 for ACC and MC4R, 1:6 for MC3R, and 2:15 for M-CPT I. PCR was performed at $94{ }^{\circ} \mathrm{C}$ denaturation for $60 \mathrm{~s}, 59{ }^{\circ} \mathrm{C}$ annealing temperature for $45 \mathrm{~s}$, and $72{ }^{\circ} \mathrm{C}$ elongation temperature for $60 \mathrm{~s}$ for 34 cycles for ACC, 32 for M-CPT I, 28 for MC3R, and 40 for MC4R. The PCR product was electrophoresed on acrylamide gel and stained with SYBR green (Molecular Probes, Eugene, OR, USA). Gels were scanned using a STORM fluorescent scanner and data analyzed using ImageQuant (Molecular Dynamics, Sunnyvale, CA, USA). The relative values of ACC, M-CPT I, MC3R, and MC4R mRNA were derived from dividing the signal obtained for the corresponding amplicon by that for the $18 \mathrm{~S}$ amplicon.

\section{Statistical analysis}

Results are presented as means \pm S.E. Unpaired two-tailed Student's $t$-test was employed for analysis of body weight and serum leptin after 10 weeks of feeding and hypothalamic MC3R/MCR4 expression levels, as well as for the comparison of the percent baseline levels of caloric intake between MTII-treated $\mathrm{CH}$ and DIO rats at day 2. For all other data, one-way or two-way ANOVA was performed. When the main effect was significant, a post hoc test (either Tukey or Bonferroni multiple comparison with the error rate corrected for the number of contrasts) was applied to determine individual differences between means. A value of $P<0.05$ was considered significant.

\section{Results}

Body weight and serum leptin levels in $\mathrm{CH}$ and DIO rats after 10 weeks of diet

At the beginning of the HF feeding period, the average body weight of $\mathrm{CH}$ and DIO rats were very similar (Table 1). By the end of the 10 weeks of HF feeding, DIO animals had gained almost twice as much weight and were nearly $40 \mathrm{~g}$ heavier than $\mathrm{CH}$ animals (Table 1). Serum
A

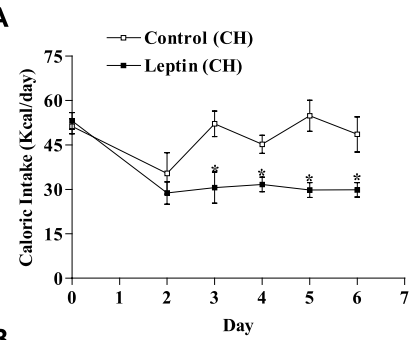

B
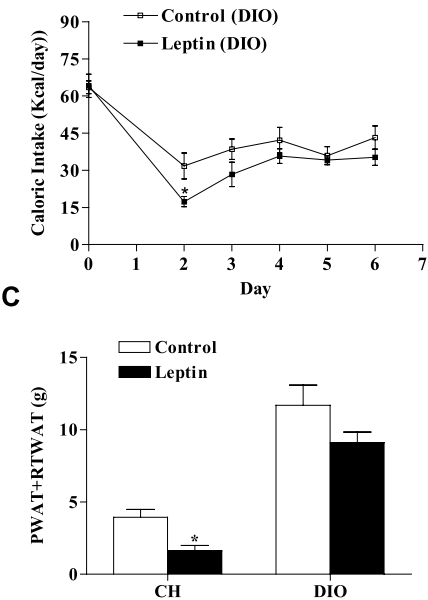

Figure 1 (A and B) Daily caloric intake and (C) visceral adiposity following 6 days of i.c.v. administration of vehicle or leptin $(10 \mu \mathrm{g} /$ day $)$ in $\mathrm{CH}$ and DIO rats. The vehicle was ACSF. Values are means \pm S.E. of five to seven animals per group. Visceral adiposity levels are represented by the sum of PWAT+RTWAT. ${ }^{*} P$ at least $<0.05$ vs corresponding controls.

leptin levels were elevated in DIO rats by more than twofold compared with $\mathrm{CH}$ rats.

Experiment 1: effects of 6-day i.c.v. leptin infusion on food intake and visceral adipose tissues in $\mathrm{CH}$ and $\mathrm{DIO}$ rats

To test whether the DIO rats were leptin resistant, we examined the responsiveness to central leptin infusion $(10 \mu \mathrm{g} /$ day $)$ in $\mathrm{CH}$ and DIO rats for 6 days. Compared with vehicle solution (ACSF), leptin induced a sustained suppression in food consumption in $\mathrm{CH}$ rats, starting at day 3 and persisting throughout the 6-day experimental period (Fig. 1A). In contrast, only a transient anorexic response to leptin was observed (day 2) in DIO rats (Fig. 1B).

The fat-reducing effect of leptin was also investigated in two major visceral fat depots, PWAT and RTWAT. The sum of PWAT and RTWAT of DIO control rats was threefold higher than that of $\mathrm{CH}$ controls (Fig. 1C). This result and the significant elevation of serum leptin levels in the obese rats indicated a dramatic increase in visceral adiposity and presumably total adiposity levels in DIO animals following HF feeding. The 6-day leptin infusion reduced the sum of PWAT and RTWAT as expected by 
59\% in CH rats compared with controls (Fig. 1C). On the contrary, visceral adiposity levels decreased only slightly in DIO rats given leptin (Fig. 1C).

\section{Experiment 2: 6-day i.c.v. MTII infusion in $\mathrm{CH}$ and DIO rats}

Food consumption and body weight To determine if the DIO rats with leptin resistance are responsive to central MC activation, the MC agonist MTII (1 nmol/ day) or ACSF was infused into the lateral ventricle for 6 days in $\mathrm{CH}$ or DIO rats. MTII induced a significant reduction in caloric intake in $\mathrm{CH}$ rats compared with the ad libitum-fed control animals (Fig. 2A). Specifically, the MTII-treated $\mathrm{CH}$ rats ate only $32 \%$ of calories consumed by control rats at day 2 , and $66 \%$ at day 6 . Despite the fact that DIO animals were more susceptible to the surgical intervention compared with $\mathrm{CH}$ ones in term of food intake (Fig. 2A and B), a phenomenon also observed in experiment 1 (Fig. 1A and B), MTII still effectively suppressed caloric intake in DIO rats to a magnitude similar to that in $\mathrm{CH}$ rats (Fig. 2B): MTII administration reduced caloric intake by $84 \%$ in DIO rats at day 2 and $31 \%$ at day 6 when compared with DIO controls.

In addition to marked anorexia, MTII also reduced body weight significantly in both $\mathrm{CH}$ and DIO rats (Fig. 2C). MTII-treated $\mathrm{CH}$ rats weighed 7.9\% less at day 6 compared with ad libitum-fed $\mathrm{CH}$ controls (Fig. 2C). In DIO rats, the average body mass decreased by $6 \cdot 5 \%$ at day 6 compared with ad libitum-fed DIO controls (Fig. 2C). Pair-feeding in this study revealed that the MTII-induced weight loss was not merely caused by the suppression in food intake. Even though both pair-fed $\mathrm{CH}$ and DIO groups lost more body weight than their respective ad libitum-fed counterparts at the end of the experiment, the MTII-treated rats on both $\mathrm{CH}$ and HF diets exhibited a further reduction in their body weight compared with their respective pair-fed groups (Fig. 2C).

Visceral adiposity, serum hormones, and metabolites As shown in Table 2, relative to the respective ad libitum-fed controls, central MTII infusion reduced visceral adiposity (represented by the sum of PWAT and RTWAT) significantly in $\mathrm{CH}(48 \%)$ and DIO (44\%) rats with similar efficacy. In contrast, pair-feeding failed to produce a significant reduction in visceral fat mass in either $\mathrm{CH}$ or DIO rats (Table 2). Whilst circulating leptin concentrations were similar between ad libitum-fed control and pair-fed groups on either $\mathrm{CH}$ or HF diets, serum leptin decreased by $59 \%$ and $69 \%$ in MTII-treated $\mathrm{CH}$ and DIO rats respectively (Table 2 ).

MTII administration also lowered serum insulin levels in $\mathrm{CH}$ and DIO rats and decreased serum glucose in DIO rats while pair-feeding itself only reduced serum glucose and insulin in DIO animals. Total serum cholesterol levels were decreased by $43 \%$ and $18 \%$ in $\mathrm{CH}$ and $\mathrm{DIO}$ rats respectively, whereas pair-feeding induced a similar effect in $\mathrm{CH}$ but only a tendency towards a decrease in DIO rats with respect to serum cholesterol levels (Table 2).

Energy expenditure Whole body oxygen consumption was assessed at day 2 and day 6 following MTII or ACSF infusion by indirect calorimetry in both $\mathrm{CH}$ and DIO animals. Oxygen consumption was elevated at day 6 (Fig. 3B) but not at day 2 (Fig. 3A) in MTII-infused $\mathrm{CH}$ rats compared with either ad libitum-fed control or pair-fed rats. In contrast, MTII induced a rapid and significant increase in oxygen consumption at day 2 in DIO rats (Fig. 3A). The decrease in food intake brought about by MTII should normally suppress energy expenditure; however, elevation of oxygen consumption occurred despite anorexia and persisted through day 6 of MTII infusion (Fig. 3B). By observation, all rats were sedentary during oxygen consumption measurements, and there were no observed differences in activity levels between groups.

Because body weight was considerably greater in the DIO compared with the $\mathrm{CH}$ rats, and MTII significantly reduced body weight in both $\mathrm{CH}$ and DIO rats, we also calculated oxygen consumption per rat rather than adjusted to lean body weight. By this calculation, there was also a significant increase in oxygen consumption with MTII compared with control or pair-fed rats (data not shown).

Induction of UCP1 in BAT is an important marker for enhanced thermogenesis or energy expenditure in rodents (Scarpace et al. 1997). In the present study, we examined the UCP1 protein levels following MTII treatment. Basal BAT UCP1 was greater than twofold higher in DIO controls compared with $\mathrm{CH}$ controls (Fig. 4), indicating that HF feeding induced UCP1 synthesis in BAT. In response to MTII administration, UCP1 levels in both $\mathrm{CH}$ and DIO rats increased significantly, whereas UCP1 levels in pair-fed rats remained unchanged as compared with respective ad libitum-fed controls (Fig. 4).

Expression of enzymes regulating fat metabolism in skeletal muscle M-CPT I and ACC are two important enzymes involved in fat metabolism in skeletal muscle. Increases in M-CPT I and decreases in ACC are consistent with enhanced fat catabolism (Jeukendrup 2002). We conducted relative quantitative RT-PCR to determine the expression levels of these two enzymes in red soleus muscle with respect to MTII treatment. The mRNA levels of either enzyme were similar among ad libitum-fed, MTII-treated and pair-fed $\mathrm{CH}$ rats. However, in DIO rats, MTII infusion prevented the dramatic reduction in M-CPT I expression by pair-feeding (Fig. 5A), and slightly but significantly reduced the mRNA levels of ACC relative to both ad libitum-fed controls and pair-fed rats (Fig. 5B). These data suggested that MTII induces fat catabolism in skeletal muscle. 
Expression of MC3R and MC4Rs in the hypothalamus The initial enhanced anorexic and thermogenic responses to MTII in the HF-fed rats prompted us to examine the expression of MC3R and MC4R in the hypothalamus. MC3R and MC4R expression levels were determined by relative quantitative RT-PCR in $\mathrm{CH}$ and DIO ad libitum-fed control rats. Surprisingly, 10 weeks of HF feeding significantly decreased MC3R and MC4R by $18 \%$ and $26 \%$ respectively (Fig. 6).

A

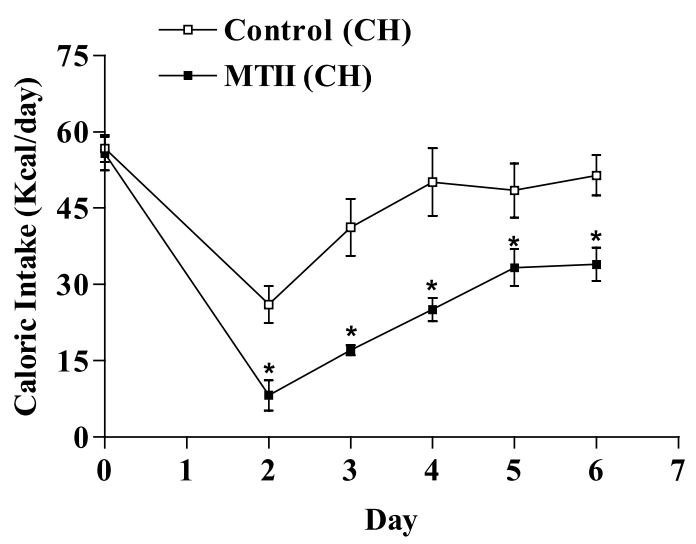

B
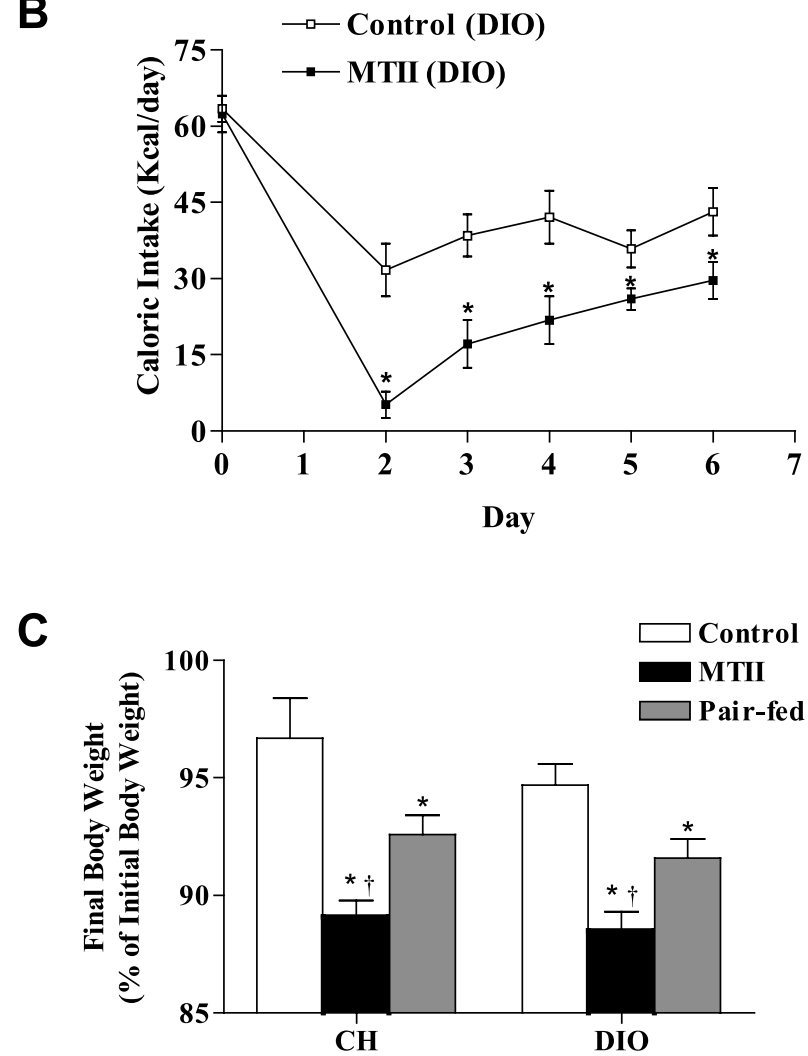

\section{Discussion}

The present study assessed the effects of MTII, a potent MC3R/MC4R agonist, on several aspects of energy regulation in a DIO rodent model. After 10 weeks of HF feeding, $40 \%$ of the female Sprague-Dawley rats became obese and displayed leptin resistance to centrally infused leptin. However, subsequent central MTII infusion circumvented leptin resistance in these DIO rats, leading to suppressed food intake, reduced body weight, and visceral adiposity.

Although in agreement with most of the earlier reports in that genetically obese and DIO animals respond robustly to $\alpha-\mathrm{MSH}$ or MTII treatment (Hansen et al. 2001, Cettour-Rose \& Rohner-Jeanrenaud 2002, Pierroz et al. 2002), our study has provided an extension of the previous knowledge. First, despite a reduction in hypothalamic MC3R and MC4R expression levels in DIO rats, the animals responded to MTII administration with similar efficacy to that of $\mathrm{CH}$ rats. Moreover, an increase in the initial energy expenditure was evident as early as day 2 in $\mathrm{DIO}$, but not apparent in $\mathrm{CH}$ rats until day 6. There is speculation that central $\mathrm{MC}$ receptor up-regulation might contribute to an enhanced anorexic response in DIO animals (Hansen et al. 2001). For instance, enhanced responses to MTII in obese Zucker rats are linked to increased hypothalamic MC4R densities (Harrold et al. 1999). Yet the same study also noted that MC4R densities in specific hypothalamic regions involved in energy regulation were actually diminished in DIO rats with a normal genetic background. Our data together with this report seem to argue against the homeostatic MC3R/MC4R up-regulation theory.

The present report also suggested that an increase in energy expenditure contributes to the loss of body weight and visceral adiposity following MTII treatment in both $\mathrm{CH}$ and DIO rats. Central MTII infusion markedly reduced body weight and visceral adiposity in obese DIO rats compared with their respective ad libitum-fed or pair-fed animals. Because pair-feeding accounts for changes due to reduced food intake, our observation is suggestive of a food intake-independent component in the fat-trimming effect of MTII. The elevation of oxygen consumption at day 2 in DIO and day 6 in $\mathrm{CH}$ and DIO

Figure 2 ( $\mathrm{A}$ and $\mathrm{B}$ ) Caloric intake and $(\mathrm{C})$ body weight of $\mathrm{CH}$ and DIO rats following 6 days of i.c.v. administration of vehicle or MTII $(1 \mathrm{nmol} /$ day). The vehicle was ACSF. Control animals were either fed ad libitum (control) or pair-fed to the amount of calories consumed by the MTII-treated groups (pair-fed). The final body weight is expressed as the percentage of initial body weight prior to the start of the experiment (day 0). Values are means \pm S.E. of six to nine animals per group. During the entire experimental period, caloric intake of pair-fed and MTII-treated rats was significantly different from the controls by repeated measures ANOVA. ${ }^{*} P$ at least $<0.05$ vs controls and $+P$ at least $<0.05$ vs pair-fed by post hoc Tukey's test. 
Table 2 Effects of 6-day i.c.v. MTII administration on visceral adiposity, serum leptin, glucose, insulin, and total cholesterol levels in $\mathrm{CH}$ and $\mathrm{DIO}$ rats. Values were measured at the end of the 6-day experimental period and are means \pm S.E. of six to nine animals per group.

$\mathrm{CH}$

\begin{tabular}{|c|c|c|}
\hline Control & MTII & Pair-fed \\
\hline $4 \cdot 61 \pm 0 \cdot 71$ & $2 \cdot 41 \pm 0 \cdot 48^{*}$ & $4 \cdot 47 \pm 1 \cdot 25$ \\
\hline $2 \cdot 63 \pm 0 \cdot 47$ & $1 \cdot 09 \pm 0 \cdot 24^{*}$ & $2 \cdot 49 \pm 1 \cdot 12$ \\
\hline $84 \cdot 1 \pm 2 \cdot 6$ & $79 \cdot 9 \pm 1 \cdot 8$ & $73 \cdot 8 \pm 8 \cdot 2$ \\
\hline $3.69 \pm 0.56$ & $1 \cdot 17 \pm 0.63^{*}$ & $2 \cdot 73 \pm 0.54$ \\
\hline $91 \cdot 7 \pm 8 \cdot 2$ & $51 \cdot 9 \pm 6 \cdot 3^{*}$ & $62 \cdot 2 \pm 5 \cdot 1^{*}$ \\
\hline
\end{tabular}

DIO

\begin{tabular}{|c|c|c|}
\hline Control & MTII & Pair-fed \\
\hline $10 \cdot 91 \pm 1 \cdot 45$ & $6 \cdot 12 \pm 0 \cdot 92^{* \dagger}$ & $9 \cdot 91 \pm 1 \cdot 37$ \\
\hline $9 \cdot 74 \pm 2 \cdot 19$ & $3 \cdot 02 \pm 0.61^{* \dagger}$ & $7 \cdot 13 \pm 1 \cdot 51$ \\
\hline $140 \cdot 5 \pm 9 \cdot 7$ & $124 \cdot 2 \pm 3 \cdot 9^{\dagger}$ & $92 \cdot 6 \pm 5 \cdot 4^{*}$ \\
\hline $4 \cdot 37 \pm 0 \cdot 82$ & $2 \cdot 05 \pm 0 \cdot 34^{*}$ & $2 \cdot 48 \pm 0 \cdot 45^{*}$ \\
\hline $120 \cdot 7 \pm 6 \cdot 0$ & $99 \cdot 1 \pm 5 \cdot 0^{*}$ & $109 \cdot 3 \pm 3 \cdot 9$ \\
\hline
\end{tabular}

MTII (1 nmol/day) or vehicle (ACSF) was infused into the left lateral ventricle for 6 days. Control animals were either fed ad libitum (control) or pair-fed to the amount of food consumed by the MTII-treated groups (pair-fed). Visceral adiposity is represented by the sum of PWAT and RTWAT.

${ }^{*} P$ at least $<0 \cdot 05$ vs control.

${ }^{\dagger} P<0.05$ vs pair-fed by one-way ANOVA with post hoc Tukey's test.

rats during central MTII infusion further argues that an increase in energy expenditure is involved. Non-shivering thermogenesis in BAT represents an essential element in adaptive energy expenditure in rodents, and the UCP1 protein level is one indicator of the thermogenic status of BAT (Nedergaard et al. 2001). A previous report indicated that animals treated with MTII had elevated levels of BAT UCP1 expression (Cettour-Rose \& Rohner-Jeanrenaud 2002). Similarly, in the present study, MTII greatly enhanced UCP1 protein levels in BAT. This substantial increase in UCP1 may well be the mediator for the elevated thermogenesis following MTII treatment. The long-term HF feeding (10 weeks) also increased basal BAT UCP1 protein levels by more than twofold. This up-regulation of basal UCP1 in BAT may serve as one explanation for the immediate increase in the MTIIinduced energy expenditure (at day 2) in DIO rats.

Humans with excessive fat deposition in the body have a high risk of various obesity-related disorders such as type 2 diabetes, heart diseases, and stroke (Gasteyger \& Tremblay 2002). MTII produced an impressive reduction in visceral adiposity in the present study, which was not matched by pair-feeding. Even though chronic caloric restriction has been shown to decrease visceral adiposity in rodents and humans (Barzilai et al. 1998, Tchernof et al. 2002), we did not observe a significant decrease in visceral fat mass in either $\mathrm{CH}$ or DIO animals pair-fed to MTII treatment. Such a discrepancy could result from the transient anorexic response to MTII. Unlike constant food restriction, pair-fed rats in our experiment were restricted to a small amount of food during the initial days of the experiment but then provided with much more food towards the later days of the treatment. This pair-feeding pattern resembles caloric restriction followed by partial refeeding. Humans and animals under this kind of feeding pattern often undergo a greater weight gain and fat repletion (Soriguer et al. 2003). In our case, a significant loss in visceral adiposity was likely prevented by this variable pair-feeding. In contrast to pair-feeding, MTII treatment clearly reduced visceral adiposity in both $\mathrm{CH}$

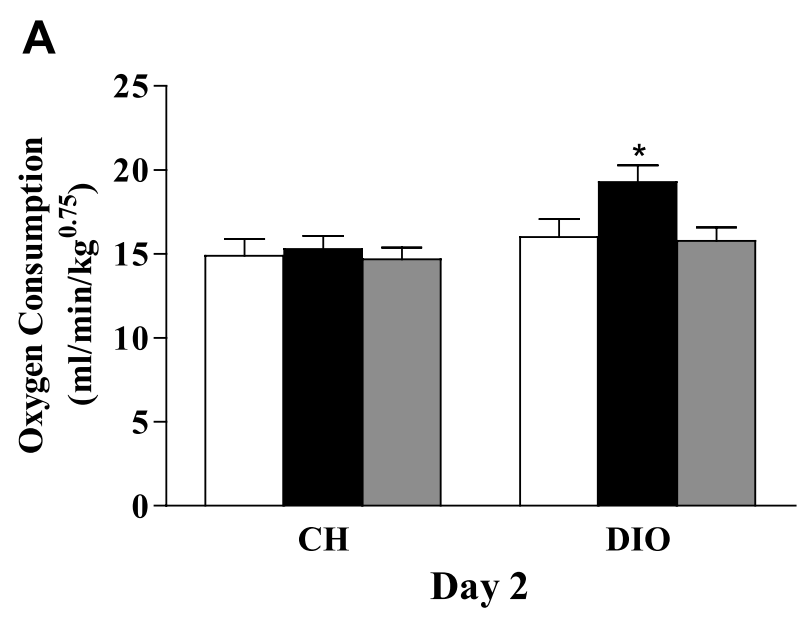

B

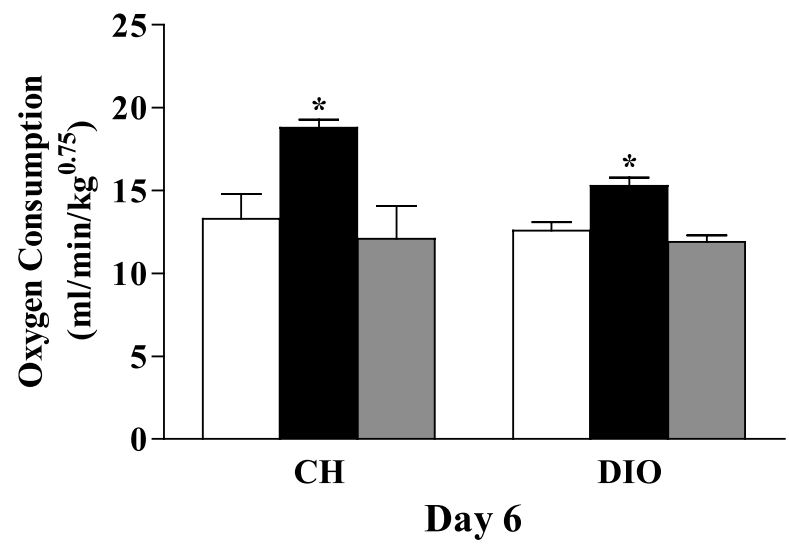

Figure 3 Energy expenditure of $\mathrm{CH}$ and $\mathrm{DIO}$ rats following 6 days of i.c.v. administration of vehicle or MTII ( $1 \mathrm{nmol} /$ day; solid bars). Control animals were either fed ad libitum (control; open bars) or pair-fed to the amount of calories consumed by the MTII-treated groups (pair-fed; shaded bars). Oxygen consumption was measured at (A) day 2 and (B) day 6 . Values are means \pm S.E. of six to nine animals per group. ${ }^{*} P$ at least $<0.05$ vs corresponding control and pair-fed groups by one-way ANOVA with post hoc Tukey's test. 


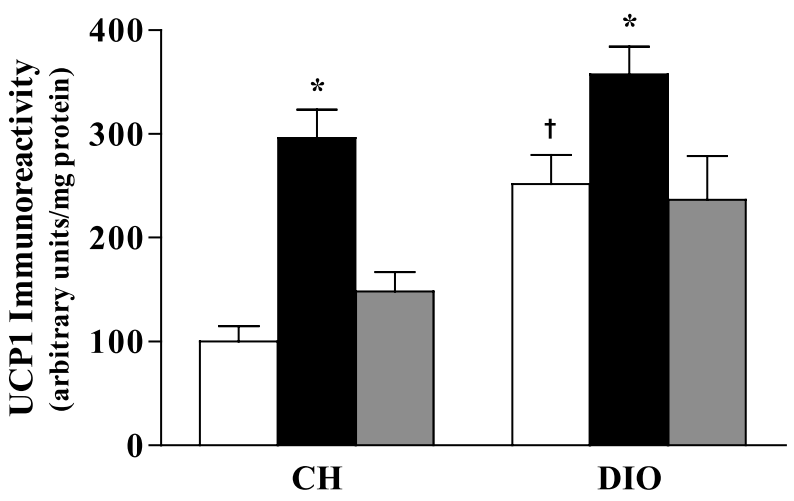

Figure 4 BAT UCP1 levels in $\mathrm{CH}$ and DIO rats following 6 days of i.c.v. administration of vehicle or MTII ( $1 \mathrm{nmol} /$ day; solid bars). The vehicle used was ACSF. Control animals were either fed ad libitum (control; open bars) or pair-fed to the amount of calories consumed by the MTII-treated groups (pair-fed; shaded bars). Values are means \pm S.E. of six to nine animals per group. UCP1 levels are expressed in arbitrary units with levels in $\mathrm{CH}$ controls set to 100 and the S.E. adjusted proportionally. ${ }^{*} P$ at least $<0.05$ vs controls and pair-fed; $\uparrow P<0.01$ vs $\mathrm{CH}$ controls by two-way ANOVA with post hoc Bonferroni test.

and DIO groups in spite of the temporal change in food intake. Therefore, the food-independent effect of MTII, presumably the increased energy expenditure as reflected by both elevated oxygen consumption and BAT UCP1, plays a crucial part in fat catabolism.

MTII has been shown to increase the expression of liver CPT I in lean and obese Zucker rats as compared with their respective pair-fed controls (Cettour-Rose \& Rohner-Jeanrenaud 2002). CPT I is a key enzyme in fat catabolism that controls the transfer of long-chain fatty acyl-CoA molecules into mitochondria where they are oxidized. Another important enzyme is ACC, the ratelimiting enzyme for malonyl-CoA formation. Malonyl$\mathrm{CoA}$ is an allosteric inhibitor of CPT I and, thus, a reduction in ACC is consistent with promotion of fat catabolism (Jeukendrup 2002). In our study, MTII not only prevented the decrease in muscle CPT I expression associated with pair-feeding, but also reduced ACC mRNA in skeletal muscle in DIO rats. The simultaneous changes in the expression of ACC and M-CPT I indicate an overall increase in fatty acid oxidation in skeletal muscles, implying that the increased fat catabolism in muscle could be an additional factor in mediating the fat-reducing action of MTII. Considering the relatively small amount of BAT versus the large volume of skeletal muscles in humans, the MTII-evoked muscle fat metabolism seems to offer a much more promising target for any potential clinical application.

Finally, MTII also appeared to improve glucose and cholesterol metabolism and insulin sensitivity. Central MCR activation can reduce insulin release from the pancreas and enhance glucose metabolism (Fan et al. 1997, Obici et al. 2001). However, the results in obese animal
A

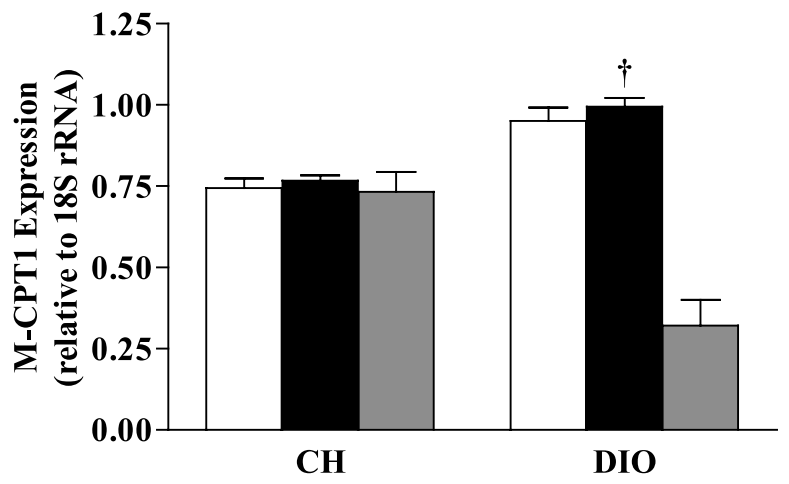

B

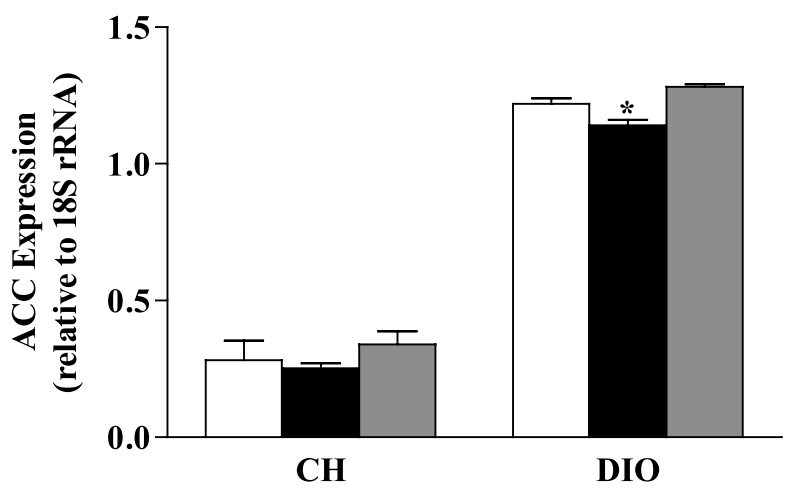

Figure 5 (A) M-CPT I and (B) ACC expression in red soleus muscle of $\mathrm{CH}$ and $\mathrm{DIO}$ rats following 6 days i.c.v. administration of vehicle or MTII ( $1 \mathrm{nmol} /$ day; solid bars). The vehicle used was ACSF. Control animals were either fed ad libitum (control; open bars) or pair-fed to the amount of calories consumed by the MTII-treated groups (pair-fed; shaded bars). Values are means \pm S.E. of six to nine animals per group. Results are normalized to $18 \mathrm{~S}$ rRNA. ${ }^{*} P<0.05$ vs corresponding control and pair-fed groups; $+P<0.01$ vs pair-fed by one-way ANOVA with post hoc Tukey's test.

models are controversial: one study suggested that peripheral but not central MTII improved insulin resistance in DIO mice (Pierroz et al. 2002), whereas another reported that 3-day peripheral MTII administration had no effect on serum insulin in obese Zucker rats (Cettour-Rose \& Rohner-Jeanrenaud 2002). In our present study, central MTII infusion resulted in significant reductions in serum insulin levels in $\mathrm{CH}$ and DIO rats and serum glucose levels in DIO rats, suggesting improved glucose metabolism and insulin sensitivity by MTII. Besides its impact on insulin and glucose, MTII also reduced total serum cholesterol levels in $\mathrm{CH}$ and DIO rats. How MTII lowers cholesterol is currently unknown. It is conceivable that, in addition to the cholesterol-reducing effect of hypophagia, insulinmediated stimulation of cholesterol synthesis diminishes following a fall in circulating insulin levels (Horton et al. 2002). 


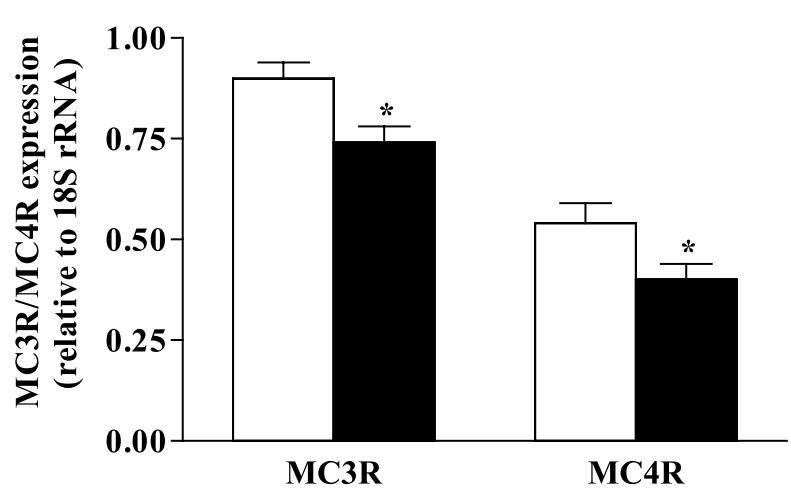

Figure 6 Hypothalamic MC3R and MC4R expression in $\mathrm{CH}$ (open bars) and DIO (solid bars) rats following 10 weeks of diet. Values are means \pm S.E. of six animals per group. Results are normalized to $18 \mathrm{~S}$ rRNA. ${ }^{*} P<0 \cdot 05$ vs controls by unpaired $t$-test.

In summary, the present study has demonstrated that central MC activation by the MC3R/MC4R agonist MTII circumvents leptin resistance associated with DIO, resulting in a reduction in body mass and visceral adiposity. Despite reduced hypothalamic MC3R/MC4R expression, the anorexic and thermogenic responses to MTII are unabated with an even more rapid onset for the increase in energy expenditure in DIO versus $\mathrm{CH}$ rats. The HF-induced up-regulation of BAT UCP1 in DIO rats may account for this immediate increase in energy expenditure following central MTII infusion. Furthermore, MTII appears to increase fat catabolism in skeletal muscle, and improve glucose and cholesterol metabolism and insulin sensitivity in both $\mathrm{CH}$ and DIO rats. The hypophagia and/or increased energy expenditure are the likely mechanisms underlying these improvements.

\section{Acknowledgements}

This work was supported by the Medical Research Service of the US Department of Veterans Affairs and NIH grant AG-17047.

\section{References}

Barzilai N, Banerjee S, Hawkins M, Chen W \& Rossetti L 1998 Caloric restriction reverses hepatic insulin resistance in aging rats by decreasing visceral fat. Journal of Clinical Investigation 101 1353-1361.

Baskin DG, Hahn TM \& Schwartz MW 1999 Leptin sensitive neurons in the hypothalamus. Hormone and Metabolic Research 31 345-350.

Burguera B, Couce ME, Curran GL, Jensen MD, Lloyd RV, Cleary MP \& Poduslo JF 2000 Obesity is associated with a decreased leptin transport across the blood-brain barrier in rats. Diabetes 49 1219-1223.

Cettour-Rose P \& Rohner-Jeanrenaud F 2002 The leptin-like effects of 3-d peripheral administration of a melanocortin agonist are more marked in genetically obese Zucker $(\mathrm{fa} / \mathrm{fa})$ than in lean rats. Endocrinology 143 2277-2283.
Chen AS, Marsh DJ, Trumbauer ME, Frazier EG, Guan XM, Yu H, Rosenblum CI, Vongs A, Feng Y, Cao L et al. 2000 Inactivation of the mouse melanocortin-3 receptor results in increased fat mass and reduced lean body mass. Nature Genetics 26 97-102.

Cheung CC, Clifton DK \& Steiner RA 1997 Proopiomelanocortin neurons are direct targets for leptin in the hypothalamus. Endocrinology 138 4489-4492.

Clegg DJ, Benoit SC, Air EL, Jackman A, Tso P, D'Alesio D, Woods SC \& Seeley RJ 2003 Increased dietary fat attenuates the anorexic effects of intracerebroventricular injections of MTII. Endocrinology 144 2941-2946.

Cone RD 1999 The central melanocortin system and energy homeostasis. Trends in Endocrinology and Metabolism 10 211-216.

Elias CF, Kelly JF, Lee CE, Ahima RS, Drucker DJ, Saper CB \& Elmquist JK 2000 Chemical characterization of leptin-activated neurons in the rat brain. Journal of Comparative Neurology 423 261-281.

El Haschimi K, Pierroz DD, Hileman SM, Bjorbaek C \& Flier JS 2000 Two defects contribute to hypothalamic leptin resistance in mice with diet-induced obesity. Journal of Clinical Investigation 105 1827-1832.

Fan W, Boston BA, Kesterson RA, Hruby VJ \& Cone RD 1997 Role of melanocortinergic neurons in feeding and the agouti obesity syndrome. Nature 385 165-168.

Gasteyger C \& Tremblay A 2002 Metabolic impact of body fat distribution. Journal of Endocrinological Investigation 25 876-883.

Graham M, Shutter JR, Sarmiento U, Sarosi I \& Stark KL 1997 Overexpression of Agrt leads to obesity in transgenic mice. Nature Genetics 17 273-274.

Grill HJ, Ginsberg AB, Seeley RJ \& Kaplan JM 1998 Brainstem application of melanocortin receptor ligands produces long-lasting effects on feeding and body weight. Journal of Neuroscience $\mathbf{1 8}$ 10128-10135.

Hagan MM, Rushing PA, Schwartz MW, Yagaloff KA, Burn P, Woods SC \& Seeley RJ 1999 Role of the CNS melanocortin system in the response to overfeeding. Journal of Neuroscience 19 2362-2367.

Hansen MJ, Ball MJ \& Morris MJ 2001 Enhanced inhibitory feeding response to alpha-melanocyte stimulating hormone in the diet-induced obese rat. Brain Research 892 130-137.

Harrold JA, Widdowson PS \& Williams G 1999 Altered energy balance causes selective changes in melanocortin-4 (MC4-R), but not melanocortin-3 (MC3-R), receptors in specific hypothalamic regions: further evidence that activation of MC4-R is a physiological inhibitor of feeding. Diabetes 48 267-271.

Horton JD, Goldstein JL \& Brown MS 2002 SREBPs: activators of the complete program of cholesterol and fatty acid synthesis in the liver. Journal of Clinical Investigation 109 1125-1131.

Huszar D, Lynch CA, Fairchild-Huntress V, Dunmore JH, Fang Q, Berkemeier LR, Gu W, Kesterson RA, Boston BA, Cone RD, Smith FJ, Campfield LA, Burn P \& Lee F 1997 Targeted disruption of the melanocortin-4 receptor results in obesity in mice. Cell 88 131-141.

Hwa JJ, Ghibaudi L, Gao J \& Parker EM 2001 Central melanocortin system modulates energy intake and expenditure of obese and lean Zucker rats. American Journal of Physiology: Regulatory, Integrative and Comparative Physiology 281 R444-R451.

Jeukendrup AE 2002 Regulation of fat metabolism in skeletal muscle. Annals of the New York Academy of Sciences 967 217-235.

Krude H, Biebermann H, Luck W, Horn R, Brabant G \& Gruters A 1998 Severe early-onset obesity, adrenal insufficiency and red hair pigmentation caused by POMC mutations in humans. Nature Genetics 19 155-157.

Li G, Klein RL, Matheny M, King MA, Meyer EM \& Scarpace PJ 2002 Induction of uncoupling protein 1 by central interleukin- 6 gene delivery is dependent on sympathetic innervation of brown adipose tissue and underlies one mechanism of body weight reduction in rats. Neuroscience $115879-889$. 
Li G, Mobbs CV \& Scarpace PJ 2003 Central pro-opiomelancortin gene delivery results in hypophagia, reduced visceral adiposity, and improved insulin sensitivity in genetically obese Zucker rats. Diabetes 52 1951-1957.

Nedergaard J, Golozoubova V, Matthias A, Asadi A, Jacobsson A \& Cannon B 2001 UCP1: the only protein able to mediate adaptive non-shivering thermogenesis and metabolic inefficiency. Biochimica et Biophysica Acta 1504 82-106.

Obici S, Feng Z, Tan J, Liu L, Karkanias G \& Rossetti L 2001 Central melanocortin receptors regulate insulin action. Journal of Clinical Investigation 108 1079-1085.

Ollmann MM, Wilson BD, Yang YK, Kerns JA, Chen Y, Gantz I \& Barsh GS 1997 Antagonism of central melanocortin receptors in vitro and in vivo by agouti-related protein. Science 278 135-138.

Pierroz DD, Ziotopoulou M, Ungsunan L, Moschos S, Flier JS \& Mantzoros CS 2002 Effects of acute and chronic administration of the melanocortin agonist MTII in mice with diet-induced obesity. Diabetes 51 1337-1345.

Poggioli R, Vergoni AV \& Bertolini A 1986 ACTH-(1-24) and alpha-MSH antagonize feeding behavior stimulated by kappa opiate agonists. Peptides 7 843-848.

Scarpace PJ, Matheny M \& Borst SE 1992 Thermogenesis and mitochondrial GDP binding with age in response to the novel agonist CGP-12177A. American Journal of Physiology 262 E185-E190.

Scarpace PJ, Matheny M, Pollock BH \& Tumer N 1997 Leptin increases uncoupling protein expression and energy expenditure. American Journal of Physiology 273 E226-E230.
Scarpace PJ, Matheny M \& Tumer N 2001 Hypothalamic leptin resistance is associated with impaired leptin signal transduction in aged obese rats. Neuroscience 104 1111-1117.

Schwartz MW, Seeley RJ, Campfield LA, Burn P \& Baskin DG 1996 Identification of targets of leptin action in rat hypothalamus. Journal of Clinical Investigation 98 1101-1106.

Schwartz MW, Seeley RJ, Woods SC, Weigle DS, Campfield LA, Burn P \& Baskin DG 1997 Leptin increases hypothalamic pro-opiomelanocortin mRNA expression in the rostral arcuate nucleus. Diabetes 46 2119-2123.

Soriguer F, Moreno F, Rojo-Martinez G, Cardona F, Tinahones F, Gomez-Zumaquero JM, Garcia-Fuentes E \& Morcillo S 2003 Redistribution of abdominal fat after a period of food restriction in rats is related to the type of dietary fat. British Journal of Nutrition $\mathbf{8 9}$ $115-122$.

Tchernof A, Nolan A, Sites CK, Ades PA \& Poehlman ET 2002 Weight loss reduces C-reactive protein levels in obese postmenopausal women. Circulation 105 564-569.

Yaswen L, Diehl N, Brennan MB \& Hochgeschwender U 1999 Obesity in the mouse model of pro-opiomelanocortin deficiency responds to peripheral melanocortin. Nature Medicine $\mathbf{5}$ 1066-1070.

Received 19 December 2003

Accepted 24 March 2004

Made available online as an

Accepted Preprint 30 March 2004 